\title{
Penerapan Arsitektur Regionalisme pada Perancangan Pusat Seni dan Budaya Melayu Indragiri di Kota Rengat
}

\section{Application of Regionalism Architecture in the Design of Malay's Indragiri Art and Culture Centre in Rengat City}

\author{
Salsabila Rivani'1), Muhammad Rijal2) \& Muhd. Arief Al-Husaini'3)* \\ 1) Mahasiswa Jurusan Arsitektur, Fakultas Teknik, Universitas Riau, Indonesia \\ 2) Dosen Jurusan Arsitektur, Fakultas Teknik, Universitas Riau, Indonesia \\ 3) Dosen Jurusan Arsitektur, Fakultas Teknik, Universitas Riau, Indonesia \\ Diterima: Agustus 2021; Disetujui: September 2021; Dipublikasi: Oktober 2021 \\ *Coresponding Email: salsabila.rivani3957@student.unri.ac.id
}

\begin{abstract}
Abstrak
Kota Rengat merupakan ibukota Kabupaten Indragiri Hulu. Kota ini terkenal akan sejarahnya sehingga dijuluki "Rengat Kota Bersejarah". Salah satu alasan Kota Rengat dijuluki demikian adalah karena kota ini memiliki banyak sejarah terutama di bidang seni dan budaya. Hal ini dibuktikan dengan adanya Kerajaan Melayu yang bernama Kerajaan Indragiri yang berada di tepi Sungai Indragiri. Akan tetapi, walaupun dijuluki sebagai kota bersejarah, pengembangan dalam bidang seni dan budaya di Kabupaten Indragiri Hulu belumlah terkoordinasi dengan baik. Untuk menampung segala bentuk seni dan budaya Melayu Indragiri, diperlukanlah wadah yang memadai. Perancangan Pusat Seni dan Budaya Melayu Indragiri ini berfungsi sebagai wadah untuk menampung segala seni dan budaya dari Melayu Indragiri itu sendiri, seperti seni tari, seni sastra, seni teater, dan sebagainya. Perancangan Pusat Seni dan Budaya Melayu Indragiri ini menerapkan prinsip-prinsip dari Arsitektur Regionalisme. Arsitektur Regionalisme merupakan gaya arsitektur yang mengambil karakteristik dari kebudayaan setempat. Arsitektur regionalisme sendiri merupakan penggabungan dari arsitektur tradisional dan arsitektur modern. Sehingga dalam perancangan ini akan mengambil karakteristik dari kebudayaan Melayu Indragiri sebagai acuan desain sekaligus menerapkan prinsip-prinsip arsitektur modern. Penggunaan arsitektur regionalisme sebagai prinsip dasar perancangan, diharapkan dapat menjadikan pusat seni dan budaya Melayu Indragiri menjadi salah satu ikon wisata budaya di Kabupaten Indragiri Hulu.
\end{abstract}

Kata Kunci: Pusat Seni dan Budaya, Melayu Indragiri, Arsitektur Regionalisme

\begin{abstract}
Rengat is the capital of Indragiri Hulu regency. The city is known for the history and it was called as "Rengat Kota Bersejarah". One of the reasons why Rengat city was called by that nickname is because Rengat city has so many history especially in art and culture aspects. It has been proven with a Malay kingdom named Indragiri kingdom which is located in Indragiri riverbank. Despite being called as a "Kota Bersejarah", the developments of Indragiri Hulu regency in art and culture aspects are not
\end{abstract}


coordinated well. Because of that, the city need a place to accommodate all of art and culture from Indragiri Hulu. Indragiri's art and culture centre planning has a function as a place to accommodate all of art and culture from malay's indragiri, like dance, literary, theater, etc. Indragiri's art and culture centre planning applies regionalism architecture's principle. Regionalism architecture is an architecture style that has characteristics from local culture. Regionalism architecture is a combination from traditional architecture and modern architecture. As such, this planning will take the characteristics from malay's indragiri as a design reference and architecture modern fundamental all at once. Regionalism architecture's application is expected to make Indragiri's art and culture centre to be an icon in Indragiri Hulu regency.

Keywords: Art and Culture Centre, Malay's Indragiri, Regionalism Architechture

How to Cite: Rivani S, Muhammad R, Muhammad A (2021Penerapan Arsitektur Regionalisme pada Perancangan Pusat Seni dan Budaya melayu Indragiri di Kota Rengat . JAUR (Journal of Architecture and Urbanism Research). 5 (1): $51-58$ 


\section{PENDAHULUAN}

Indragiri Hulu merupakan salah satu kabupaten yang ada di Provinsi Riau. Luas wilayah Kabupaten Indragiri Hulu meliputi $8.198,26 \mathrm{Km} 2(819.826,0 \mathrm{Ha})$ yang terdiri dari dataran rendah, dataran tinggi dan rawa-rawa dengan ketinggian 5-100 $\mathrm{m}$ di atas permukaan laut (BPS, 2019). Kabupaten Indragiri Hulu berbatasan dengan Kabupaten Kuantan Singingi di sebelah barat, Kabupaten Indragiri Hilir di sebelah timur, Kabupaten Pelalawan di sebelah utara, dan Provinsi Jambi di sebelah selatan. Ibukota dari Kabupaten Indragiri Hulu adalah Rengat. Kota Rengat sendiri merupakan sebuah kota yang berada di dekat Sungai Indragiri. Sungai Indragiri sendiri merupakan jalur transportasi utama masyarakat Indragiri Hulu di masa lampau.

Indragiri dahulu merupakan sebuah kerajaan yang bernama Kerajaan Indragiri. Kerajaan Indragiri merupakan salah satu kerajaan melayu yang ada di Provinsi Riau. Kerajaan Indragiri sendiri berpusat di beberapa daerah di Kabupaten Indragiri Hulu, salah satunya adalah Kota Rengat. Lokasi terakhir Kerajaan Indragiri terletak di tepi Sungai Indragiri. Adapun bukti yang tersisa dari Kerajaan Indragiri adalah replika Istana Kerajaan Indragiri yang terletak di antara Danau Raja dan Sungai Indragiri.

Rengat dikenal dengan julukan yang bernama Rengat Kota Bersejarah. Alasan Rengat dijuluki demikian adalah karena Rengat sangat terkenal dengan sejarahnya. Hal ini tak lepas dari eksistensi Kerajaan Indragiri itu sendiri. Kabupaten Indragiri Hulu memiliki banyak aset seni dan budaya melayu, baik itu dibidang seni tari, seni musik, seni sastra, dan seni pertunjukan yang tersebar di seluruh kecamatan di Kabupaten Indragiri Hulu. Walaupun karakteristik seni dan budaya yang ada di Kabupaten Indragiri Hulu hampir sama dengan kabupaten-kabupaten di Provinsi Riau, Kabupaten Indragiri Hulu memiliki keistimewaan tersendiri karena terdapat suku Melayu Tua, yaitu suku Talang Mamak dan suku Kubu. Sangat disayangkan, perkembangan seni dan budaya melayu Indragiri itu sendiri belum terkoordinasi dengan baik. Hal ini dapat dilihat dari data jumlah pusat wisata budaya di Kabupaten Indragiri Hulu tahun 2018 hanya berjumlah lima buah. Hal ini sangat disayangkan mengingat Kabupaten Indragiri Hulu memiliki banyak aset seni dan budaya melayu yang harus diperkenalkan kepada semua masyarakat, baik di dalam Kabupaten Indragiri maupun di luar Kabupaten Indragiri. Hal inilah yang menjadi landasan penulis dalam Perancangan Pusat Seni dan Budaya Melayu Indragiri. Penulis berharap bahwa Pusat Seni dan Budaya Melayu Indragiri ini akan berguna di segala bidang, baik itu dibidang pendidikan, maupun dibidang pariwisata.

Perancangan Pusat Seni dan Budaya Melayu Indragiri ini dilakukan dengan penerapan prinsip-prinsip regionalisme dalam arsitektur. Paham regionalisme berkembang pada masa Modernisme yang berpihak pada ciri kedaerahan, yang berkaitan dengan iklim, budaya setempat, serta teknologi yang digabungkan antara Modern dengan lokal (Menuju et al., 2017). Perancangan ini dirancang dengan menerapkan prinsip-prinsip lokal yang ada di Kabupaten Indragiri Hulu yang dikombinasikan dengan prinsip arsitektur modern.

Adapun permasalahan yang akan dikaji adalah sebagai berikut: Bagaimana kebutuhan fasilitas yang dapat mewadahi segala aktivitas pada Perancangan Pusat Seni dan Budaya Melayu Indragiri di Kota Rengat?, Bagaimana penerapan prinsip desain Arsitektur Regionalisme pada Perancangan Pusat Seni dan Budaya Melayu Indragiri di Kota Rengat?, Bagaimana penerapan konsep pada Perancangan Pusat Seni dan Budaya Melayu Indragiri di Kota Rengat?. 
Pusat dalam Kamus Besar Bahasa berarti pokok pangkal atau yang menjadi pumpunan (berbagai-bagai urusan, hal, dan sebagainya). Sedangkan Pusat Kebudayaan dalam Kamus Besar Bahasa Indonesia berarti tempat membina dan mengembangkan kebudayaan. Menurut Dosen Universitas Pendidikan Indonesia, Drs. Harry Sulastianto, M.Sn. Seni dan budaya adalah sebuah keahlian dalam aktivitas mengekspresikan ide - ide dan pemikiran estetika, termasuk mewujudkan kemampuan dan imajinasi pandangan atas bebeberapa benda, karya, atau pun suasana, yang dapat menghadirkan rasa indah dan menciptakan peradaban manusia yang lebih maju. Sedangkan menurut Merriam Webster, seni adalah lukisan, patung, musik, teater, literatur, dan lain-lain, yang dikelompokkan sebagai suatu aktivitas yang dilakukan orangorang dengan kemampuan dan imajinasi.

Regionalisme dalam Kamus Besar
Bahasa Indonesia berarti ilmu yang menyangkut kedaerahan. Menurut William Curtis (1985), Regionalisme diharapkan dapat menghasilkan bangunan yang bersifat abadi, melebur atau menyatu antara yang lama yang baru, antara regional dan universal. Arsitektur Regionalisme erat kaitannya dengan Arsitektur Tradisional. Adapun perbedaan diantara keduanya ialah Arsitektur Tradisional bersifat regional, akan tetapi Arsitektur Regionalisme sudah bercampur dengan Arsitektur modern yang bersifat universal.

\section{METODE PENELITIAN}

Perancangan Pusat Seni dan Budaya Melayu Indragiri di Kota Rengat berfungsi sebagai wadah menampung segala seni dan budaya yang ada di Kabupaten Indragiri Hulu. Sebagai Kota Bersejarah, sangat disayangkan jika Kabupaten Indragiri Hulu belum memiliki sarana yang memadai untuk mewadahi dan memperkenalkan seni dan budaya Melayu Indragiri Hulu. Perancangan Pusat Seni dan Budaya Melayu Indragiri di Kota Rengat menerapkan prinsip-prinsip Arsitektur Regionalisme dalam rancangannya.

Strategi perancangan terdiri dari beberapa tahapan, seperti survei, analisa fungsi dan aktivitas, analisa site, zoning, konsep, bentukan, struktur, utilitas, dan hasil desain.

Metode pengumpulan data dilakukan dengan membagi data menjadi data primer dan data sekunder. Data primer diperoleh dengan melakukan observasi, seperti survei dan dokumentasi. Sedangkan data sekunder diperoleh dari literatur.

\section{HASIL DAN PEMBAHASAN}

Lokasi berada di Kelurahan Kampung Dagang, Kecamatan Rengat, Kabupaten Indragiri Hulu dengan luas lahan $2 \mathrm{Ha}$. Koefisien Dasar Bangunan 50\% dengan kontur tanah relatif datar.

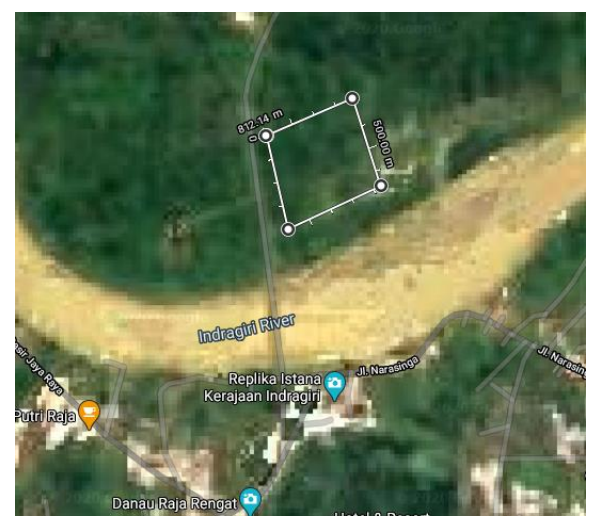

Gambar 1. Lokasi Perancangan

Sumber: Analisa Penulis, 2021

\section{Kebutuhan Ruang}

Pembagian kebutuhan ruang dibagi menjadi menjadi kebutuhan ruang kelompok kegiatan utama, kebutuhan ruang kelompok kegiatan penunjang, dan kebutuhan ruang parkir.

Tabel 1. Kebutuhan Ruang

\begin{tabular}{|l|l|}
\hline Ruang & Luas (m2) \\
\hline $\begin{array}{l}\text { Ruang Pengunjung dan } \\
\text { Seniman }\end{array}$ & $3.932,6$ \\
\hline Ruang Pengelola & 813,4 \\
\hline Ruang Parkir & 15600 \\
\hline Total & 20.346 \\
\hline
\end{tabular}

Sumber: Analisa Penulis, 2021 


\section{Penzoningan}

Penzoningan dilakukan dengan membagikan zoning sesuai dengan sifat ruang publik, yaitu ruang publik terbuka dan ruang publik tertutup. Ruang publik terbuka merupakan ruang publik bersifat outdoor, sedangkan ruang publik tertutup bersifat indoor. Ruang publik indoor memiliki fungsi edukasi dan promosi seni dan budaya Melayu Indragiri, sedangkan ruang publik outdoor memiliki fungsi rekreasi.

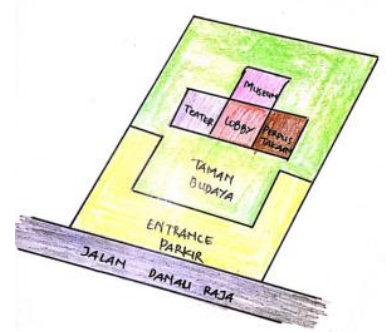

Gambar 2. Penzoningan

Sumber: Analisa Penulis, 2021

\section{Analisis Tapak}

Analisis Matahari

Salah satu cara untuk mengurangi kadar sinar matahari yang masuk ke dalam tapak, diletakkan vegetasi berupa pohon-pohon rindang sebagai peneduh. Pohon-pohon ini tidak hanya berfungsi sebagai peneduh dari sinar matahari, akan tetapi pohon-pohon ini juga akan memberikan sirkulasi udara yang bagus sehingga udara yang masuk ke dalam tapak berada dalam kapasitas yang sesuai.

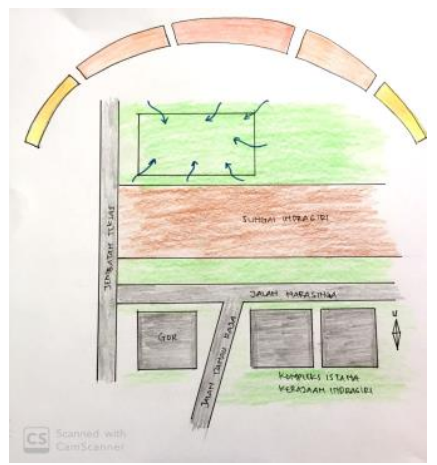

Gambar 3. Analisis Matahari Sumber: Analisa Penulis, 2021

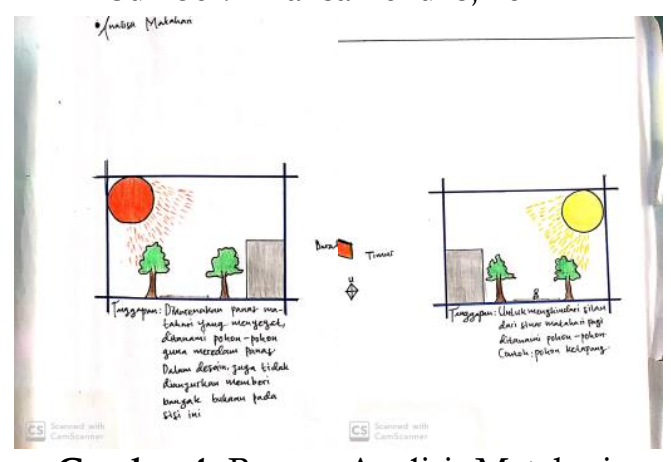

Gambar 4. Respon Analisis Matahari Sumber: Analisa Penulis, 2021

Analisis Kebisingan

Lokasi Perancangan Pusat Seni dan Budaya Melayu Indragiri bukan merupakan lokasi padat penduduk, sehingga kebisingan yang bersumber dari aktivitas di luar tapak tidak begitu berpengaruh. Untuk mengatasi kebisingan dalam tapak, dapat dilakukan dengan perletakan vegetasi untuk meredam suara yang ada di luar bangunan untuk tidak masuk ke dalam ruangan. Selain itu, penggunaan material bangunan juga berpengaruh untuk meredam kebisingan di luar bangunan.

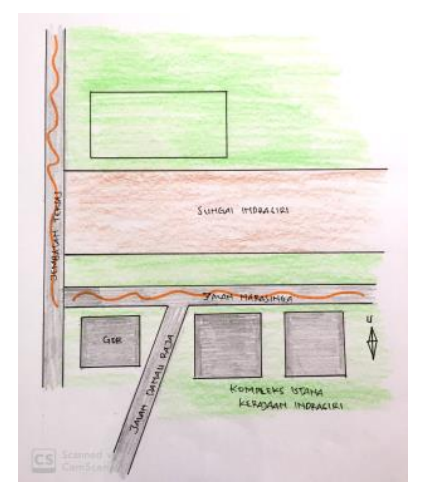

Gambar 5. Analisis Kebisingan 
Sumber: Analisa Penulis, 2021

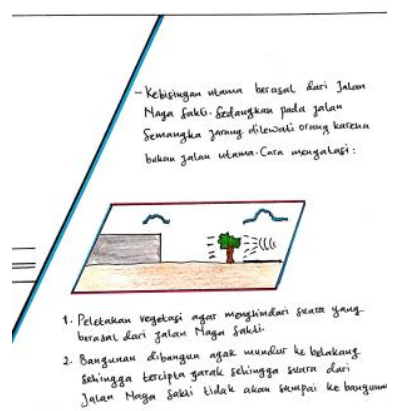

cs $5 \sin ^{-1}$

Gambar 6. Respon Analisis Kebisingan

Sumber: Analisa Penulis, 2021

\section{Analisis Vegetasi}

Pada lokasi Perancangan Pusat Seni dan Budaya Melayu Indragiri, lokasi tersebut merupakan lahan perkebunan milik warga. Adapun upaya yang dilakukan adalah mengatur vegetasi yang sudah ada di tapak, baik itu pengurangan vegetasi yang dianggap tidak perlu, maupun penambahan vegetasi yang memiliki fungsi-fungsi tertentu.

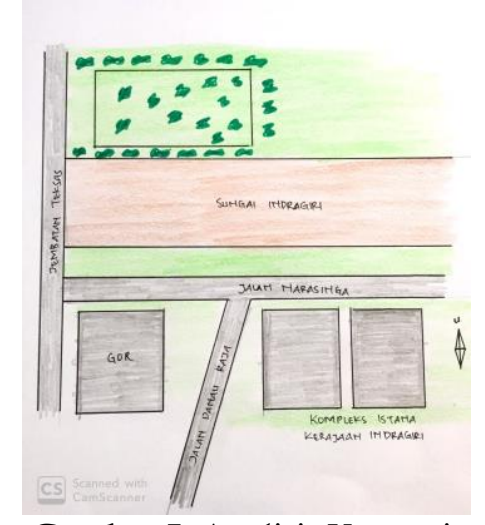

Gambar 7. Analisis Vegetasi

Sumber: Analisa Penulis, 2021

Konsep dasar perancangan adalah "Rakit Kulim". Rakit kulim merupakan sebuah salah satu transportasi bersejarah di Kabupaten Indragiri Hulu. Rakit kulim sendiri merupakan sebuah rakit dengan material kayu kulim. Sejarah rakit kulim sendiri merupakan sebuah momen penting, oleh karena itu nama Rakit Kulim dijadikan sebagai salah satu kecamatan di Kabupaten Indragiri Hulu.

Penerapan "rakit kulim" pada konsep perancangan adalah dengan memakai bentuk rakit itu sendiri menjadi bentuk bangunan. Rakit dijadikan fungsi estetika sekaligus fungsi struktur. Dengan mengganti material dari kayu kulim menjadi baja untuk fungsi kekuatan.

Pemakaian ornamen-ornamen yang ada pada rumah tradisional melayu Indragiri Hulu juga diterapkan pada perancangan ini. Ornamen-ornamen ini akan diaplikasikan pada fungsi eksterior dan fungsi interior. Hal ini bertujuan untuk menciptakan kesan tradisional dari Kabupaten Indragiri Hulu.

\section{Transformasi Konsep Arsitektural}

Transformasi konsep pada Perancangan Pusat Seni dan Budaya Melayu Indragiri dilakukan dengan cara penggabungan dari unsur-unsur ikonik Kabupaten Indragiri Hulu, yaitu bentukan rakit kulim dan elemen-elemen tradisional rumah melayu Indragiri Hulu.

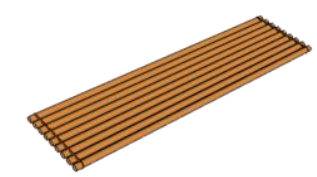

Gambar 8. Transformasi Rakit

Sumber Gambar: Analisa Penulis, 2021

Pengaplikasian ornamen-ornamen yang ada pada rumah tradisional Melayu Indragiri Hulu dilakukan untuk menciptakan kesan tradisional pada perancangan. Ornamen ini didapatkan pada ikon-ikon Kabupaten Indragiri Hulu, seperti Istana Kerajaan Indragiri dan Rumah Tinggi Indragiri Hulu. 

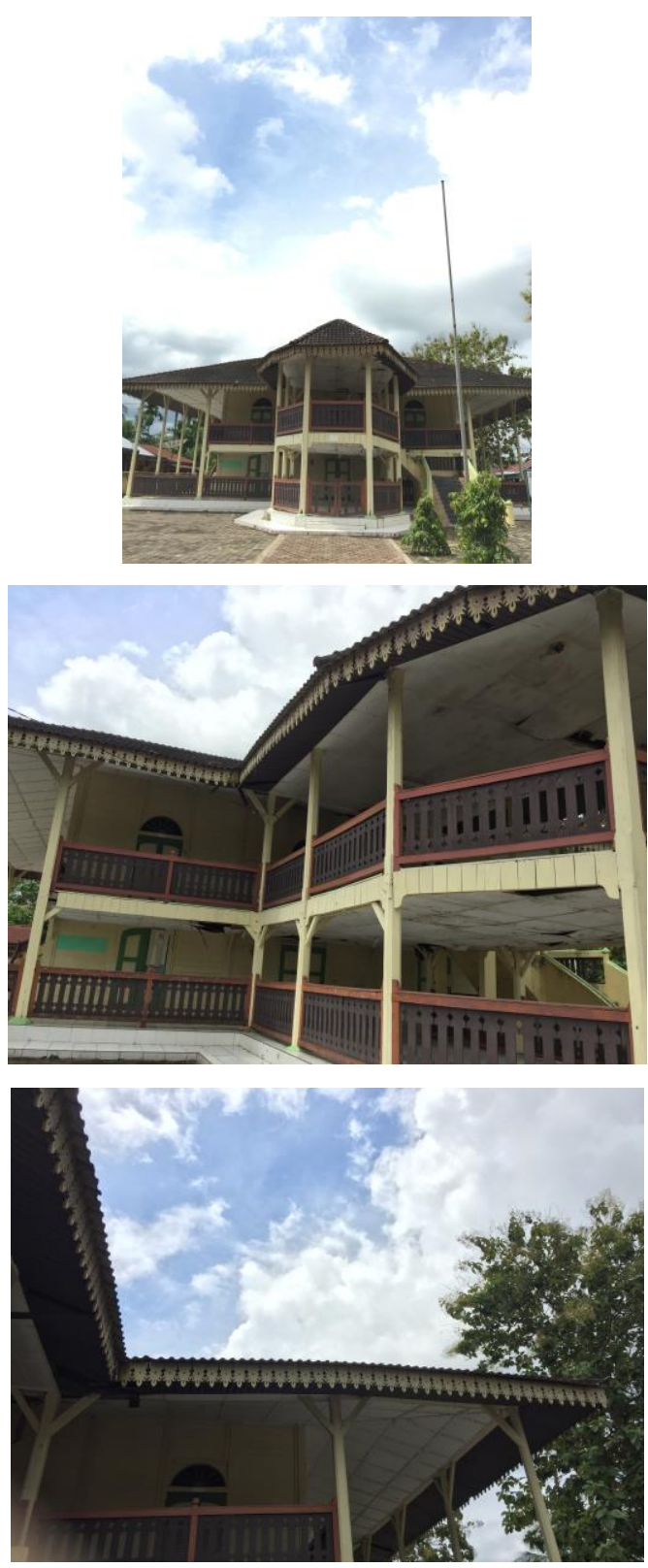

Gambar 9. Rumah Tinggi

Kabupaten Indragiri Hulu

Sumber Gambar: Analisa Penulis, 2021

Pada pengolahan tapak, konsep didapat dari hasil analisa tapak. Adapun hasil tersebut didasari oleh pembagian zonasi, yaitu ruang publik terbuka dan ruang publik tertutup. Adapun ruang publik terbuka ialah bangunan indoor yang merupakan fungsi utama dari Perancangan Pusat Seni dan Budaya Melayu Indragiri. Sedangkan ruang publik terbuka meliputi ruang outdoor, seperti lahan parkir, taman budaya, dan promenade Sungai Indragiri

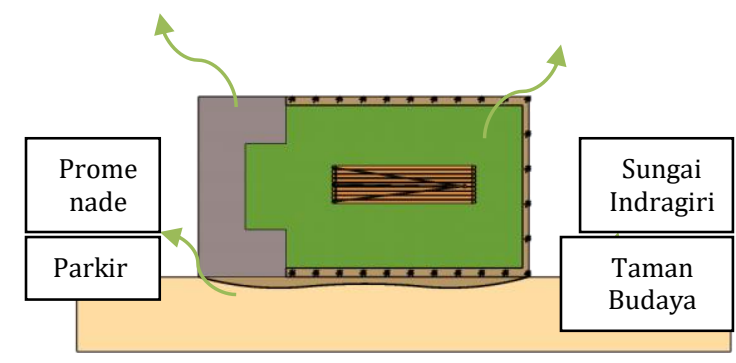

Gambar 10. Pengolahan Tapak

Sumber Gambar: Analisa Penulis, 2021

Konsep Gubahan Massa, dari

Perancangan Pusat Seni dan Budaya

Melayu Indragiri berasal dari bentuk rakit

kulim. Rakit kulim sendiri merupakan kendaraan masa lampau yang menjadi salah satu sejarah di Kabupaten Indragiri Hulu.

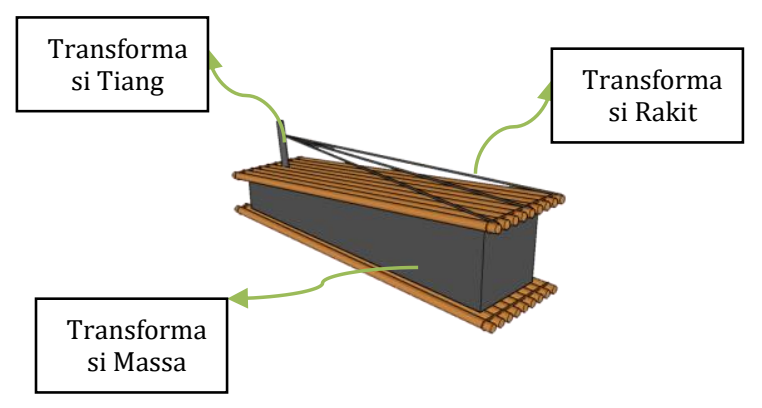

Gambar 10. Gubahan Massa

Sumber: Analisa Penulis, 2021

\section{SIMPULAN}

Pusat Seni dan Budaya Melayu Indragiri merupakan pusat apresiasi segala seni dan budaya Melayu Indragiri khususnya Kabupaten Indragiri Hulu. Kurangnya kesadaran masyarakat Kabupaten Indragiri Hulu dalam mengapresiasi seni dan budaya Melayu Indragiri menjadi alasan utama penulis merancang Pusat Seni dan Budaya Melayu Indragiri di Kota Rengat. Pendekatan arsitektur regionalisme menjadi tema yang 
dipilih pada perancangan ini dikarenakan pendekatan ini merupakan penggabungan dari arsitektur tradisional dan arsitektur modern. Hal ini bertujuan untuk menjaga kesinambungan tema dan objek perancangan. Adapun prinsip arsitektur tradisional yang digunakan adalah memakai bentukan dari sejarah Rakit Kulim dan pengaplikasian ornamen-ornamen yang ada di rumah

\section{DAFTAR PUSTAKA}

Akhir, T., Studi, P., Arsitektur, T., Teknik, F., \& Sriwijaya, U. (2018). Perencanaan dan Perancangan Pusat Seni Sumatera Selatan di Kota Palembang.

Bothwell, K. 2015. Sustainable Architecture. In Routledge International Handbook of Sustainable Development (pp. 147-163). Taylor and Francis Inc. https://doi.org/10.1145/2797433.2797496

BPS. (2019). Indragiri Hulu Dalam Angka. Kota Kediri Dalam Angka, 1-68.

Canizaro, V. B. (2014). Regionalism and Modernity: Architecture in Western Europe 1914-1940. Journal of Architectural Education, 68(1), 116-118. https://doi.org/10.1080/10464883.2014.86 $\underline{4900}$

Dharma, A. (1974). Aplikasi Regionalisme Dalam Desain Arsitektur, (November), 1-5.

Dinas Pemuda Olahraga Budaya dan Pariwisata Kabupaten Indragiri Hulu. 2010. Profil Seni Budaya. Indragiri Hulu: Pemerintah Kabupaten Indragiri Hulu

Effendy, Tenas dan Emmy Kadir. 2003. Ragam Hias pada Rumah Melayu. Pekanbaru: Sebati Riau Art Gallery dan P.T Caltex Pacific Indonesia tradisional Melayu Indragiri Hulu. Untuk prinsip arsitektur modern, dapat terlihat dari material yang digunakan dan memakai banyak bukaan kaca. Penggabungan ini sangat berperan penting dalam menghasilkan objek perancangan yang memiliki unsur-unsur khas Kabupaten Indragiri Hulu dengan desain bangunan yang up-to-date.

Hidayatun, M. I., Prijotomo, J., \& Rachmawati, M. (2012). Regionality and Regionalism in Architectural Views. Journal of Basic and Applied Scientific Research, 2(7), 7147-7152.

Kinerja, S., Terminal, C. C., Udara, B., Babullah, S., Terhadap, T., Pelayanan, T., \& Asdam, A. S. (2013). Tugas akhir, 1-74.

Mahastuti, N. M. M. (2016). Arsitektur Regionalisme di Bali.

Malang, I. 2015. Perancangan Pusat Seni Budaya Minangkabau di Kota Pariaman dengan Tema Reinterpreting Tradition

Menuju, C., Tanggap, A., Berkelanjutan, G. A. N., Adrian, P., \& Moojen, J. (2017). Latar Belakang Metodologi. X(2), 73-84.

Samin, S.M. 2007. Mengembalikan Kejayaan Melayu di Indragiri. Rengat: Alaf Riau dan Pustaka Pelajar

Sukarno, R.A dan Nirwansjah, R. 2019. Pendekatan Regionalisme dalam Redesain Museum Majapahit. Jurnal Sains dan Seni ITS, 7(2). https://doi.org/10.12962/i23373520.v7i2.3 $\underline{3576}$ 